BMJ Open

Sport \&

Exercise

Medicine

\section{Facilitators and barriers for implementation of a load management intervention in football}

To cite: Dalen-Lorentsen T, Ranvik A, Bjørneboe J, et al, Facilitators and barriers for implementation of a load management intervention in football. BMJ Open Sport \& Exercise Medicine 2021;7:e001046. doi:10.1136/ bmjsem-2021-001046

- Additional supplemental material is published online only. To view, please visit the journal online (http://dx.doi. org/10.1136/bmjsem-2021 001046).

Accepted 7 June 2021

Check for updates

\section{(c) Author(s) (or their} employer(s)) 2021. Re-use permitted under CC BY-NC. No commercial re-use. See rights and permissions. Published by BMJ.

${ }^{1}$ Oslo Sports Trauma Research Center, Department of Sports Medicine, Norwegian School of Sports Sciences, Oslo, Norway ${ }^{2}$ Centre for Disease Burden, Norwegian Institute of Public Health, Bergen, Norway

Correspondence to Torstein Dalen-Lorentsen; torstein.dalen@nih.no

\section{ABSTRACT}

Background In a recent randomised controlled trial, we found that a commonly used training load management approach was not effective in preventing injuries and illnesses in Norwegian elite youth footballers.

Aim To investigate players' and coaches' barriers and facilitators to a load management approach to prevent injuries and illnesses and their attitudes and beliefs of load management and injuries and illnesses in general.

Methods We asked players and coaches about their views on injury risk in football, the benefits and limitations of load management in general and implementation of load management in football. The questionnaires used were based on similar studies using the Reach, Effectiveness, Adoption, Implementation and Maintenance framework. Results We recorded answers from 250 players and 17 coaches. Most players (88\%) reported that scientific evidence showing improved performance from the intervention measures is a key facilitator to completing the intervention. Similarly, coaches reported that the most important facilitator was scientific evidence that the preventive measures were effective (100\%). Players reported that the coach's attitude to preventive measures was important $(86 \%)$, and similarly, $88 \%$ of coaches reported that the player's attitude was important. Conclusions By having a mutual positive attitude towards the intervention, players and coaches can positively contribute to each other's motivation and compliance. Both players and coaches reported scientific evidence for load management having injury-preventive and performance-enhancing effect and being time efficient as important facilitators.

\section{Trial registration number Trial registration number}

\section{INTRODUCTION}

Injuries are common among football players, and at both the elite youth and professional level, players can on average expect around two injuries per season. ${ }^{1-3}$

Also, at any given time of the season, the prevalence of health problems (both injuries and illnesses) exceeds $40 \%$ among elite youth players. ${ }^{3}$ Health problems and the associated loss in participation can negatively affect players' performance, ${ }^{4}$ their health later in
What is already known?

A high compliance is needed to test the real effec tiveness of an intervention.

- Many preventive measures are not well adopted by coaches, players and other stakeholders, limiting their effectiveness.

- There is a need to create buy-in from club and federation stakeholders, coaches and players when implementing injury preventive measures.

\section{What are the new findings?}

To create interventions that will be implemented, a focus on time-effective easy-to-use measures is key.

- Engage coaches, players and other stakeholders when designing and implementing an intervention.

- To get coach, player and other stakeholder buy-in, focus on both performance and prevention.

the career ${ }^{56}$ and, ultimately, their long-term professional development. $^{7}$

Training load has recently emerged as a potential risk factor for injuries in football..$^{8-11}$ Subsequently, many teams, particularly those at an elite level, attempt to manage players' training loads as a preventative measure to mitigate injuries. ${ }^{12}{ }^{13}$ However, the evidence supporting this practice is limited to observational studies of associations between training load and injuries. In a recent randomised controlled trial (RCT), ${ }^{14}$ we found that a common model of training load management using the Acute:Chronic Workload Ratio concept ${ }^{15}$ did not reduce the prevalence of health problems (both injuries and illnesses) among elite youth footballers of both sexes. Players' reported compliance with our intervention was $63 \%$. This is comparable to previous studies investigating other preventive interventions using a similar research design. $^{1617}$

Previous studies have shown that the higher the compliance, the better the effectiveness of 
the intervention. ${ }^{18-20}$ Consequently, an understanding of how compliance can be increased is warranted. Regardless of the effect of the intervention, a study examining the implementation can be of value to practitioners and researchers aiming to employ a load management programme in teams and other athlete cohorts.

The Reach, Effectiveness, Adoption, Implementation and Maintenance (RE-AIM) ${ }^{21}$ framework was first introduced in sports medicine research by Finch and Donaldson, ${ }^{22}$ to help researchers better understand the real-world implementation challenges. Using this framework, an intervention can be seen through the lens of five different dimensions to determine whether the intervention is feasible in a real-world setting. Suppose an intervention that has been deemed effective in controlled settings is not adopted, complied with and sustained. In that case, it is not likely to mitigate injuries and illnesses. ${ }^{22}$ The RE-AIM framework has previously been used in similar populations and has guided the implementation of various preventive measures in sports. ${ }^{23-25}$

To guide practitioners towards successful implementation and researchers in future implementation studies, we used questionnaires based on the RE-AIM framework to investigate players' and coaches' experiences from a load management intervention and their attitudes and beliefs to load management and injuries and illnesses in general.

\section{MATERIALS AND METHODS \\ Study design and participants}

The survey was conducted in November 2018 as a part of a cluster-RCT investigating the preventive effect of a load management approach on injuries and illnesses in Norwegian elite youth footballers of both sexes. ${ }^{14}$ The RCT was cluster randomised on a team level and consisted of a control group and an intervention group. The intervention entailed coaches adapting to an Acute:Chronic Workload theory-based load management programme. The players in the intervention group recorded their session perceived rating of exertion after every footballing activity on a smartphone application. The training load data were uploaded to an online athlete management system, where the coach could manage their training load. The control group did not record any training load data and performed training as usual. The main outcome of this study was the difference in the reported prevalence of health problems in the two groups. We observed no effect of the intervention on either outcome. The study was registered with the International Standard RCT Number registry, reviewed by the South-Eastern Norway Regional Committee for Medical and Health Research Ethics (2017/2232) and approved by the ethics board of The (39-191217) and the Norwegian Center for Research Data (56935). After the end of the 2018 season, we invited all teams that had completed the RCT to participate (25 teams, 482 players) in the survey. This report is prepared according to the STROBE-SIIS checklist for observational studies. ${ }^{26}$

\section{Patient and public involvement}

Coaches were involved in the design of the intervention and recruitment of teams and players to the study. Coaches and players were not involved in the design of the research questions, the outcome measures or the analyses. The results from the study will be disseminated to all teams that were included in the project.

\section{QUESTIONNAIRE}

The questionnaires were influenced by the reach, adoption and implementation pillars of the RE-AIM framework $^{27}$ and two similar questionnaires used to examine the implementation of the Oslo Sports Trauma Research Centre Shoulder Injury Prevention Programme in handball players ${ }^{24}$ and the Adductor Strengthening Programme in football players. ${ }^{23}$ The overall theme of the questionnaires was player's and coach's barriers and facilitators for implementation of load management to prevent injuries and illnesses and their attitudes and beliefs of load management and injury and illness in general. The questionnaires differed in two ways (1) coaches were asked specific questions on their role in the intervention and their perception of the players and vice versa and (2) the players and coaches in the intervention group were asked additional questions regarding their experiences of the intervention (for complete questionnaires, see online supplemental file 1). We conducted a pilot test with two players and one coach from a similar youth elite football setting to test their understanding of the questions, the length of the questionnaire and the technical procedures. The questionnaires that were tested were the intervention group player and coach questionnaires, as they include all the questions from the control group questionnaires, in addition to the specific intervention questions. A research staff member interviewed the players and coaches. All agreed that the questions were clear and relevant, the overall length of the questionnaire acceptable and the technical solutions suitable. No changes were made based on the pilot study, as we considered the face validity of the study to be strong. Four versions of the questionnaires were developed; one for the intervention group players, one for the intervention group coaches and one for the control group players and the control group coaches. The questionnaires were in Norwegian, as all players and coaches participating were familiar with the Norwegian language.

\section{DATA COLLECTION}

Teams that agreed to participate received a questionnaire distributed using online survey software (Briteback AB, V.2.5.3.1; Norrköping, Sweden). The data collection started as soon as the teams completed their competitive season, and, hence, were finished as participants in the RCT. The questionnaires were distributed at $9 \mathrm{pm}$ on a weekday when all other activities (ie, schoolwork and training) were likely to be completed. Players who did not respond to the initial questionnaire received a reminder 24 hours after the first distribution. Two weeks after the 
Table 1 Participant characteristics, $\mathrm{n}(\%)$

\begin{tabular}{lccl}
\hline & Male & Female & Total \\
\hline Intervention group & $74(69)$ & $33(31)$ & 107 \\
Control group & $91(64)$ & $52(36)$ & 143 \\
Total & $165(66)$ & $85(34)$ & 250
\end{tabular}

Coaches (\%)

\begin{tabular}{lclr} 
Intervention group & $8(100)$ & $0(0)$ & 8 \\
Control group & $7(78)$ & $2(22)$ & 9 \\
Total & $15(88)$ & $2(12)$ & 17 \\
\hline
\end{tabular}

initial round of distribution, all nonrespondents were sent the questionnaire again as well as the 24 hours postreminders. If certain teams had many nonrespondents, their coach was asked to encourage their players to fill in the questionnaire. Also, respondents were encouraged to contact the research group to clarify any questions they had concerning the questionnaire's content before filling it in. The questionnaires allowed players to send incomplete responses, and all responses were considered in our analyses.

\section{ANALYSIS}

All returned questionnaires were included in the analysis regardless of missing items. All responses were exported into Microsoft Excel (V.16, Microsoft Redmond, Washington) and analysed using descriptive statistics. We have not performed any between-group comparisons, but players and coaches are shown in groups in the Results section.

\section{RESULTS}

\section{Participant characteristics}

Twenty-three of the 25 teams in the RCT participated in the survey. In total, $250(51 \%)$ of the players enrolled at baseline were included, $107(46 \%)$ of the intervention group and $143(58 \%)$ of the control group, respectively. Seventeen coaches $(68 \%)$ were included, $8(73 \%)$ from the intervention group and 7 (50\%) from the control group, respectively. Participant characteristics are shown in table 1.

\section{Barriers and facilitators to load management implementation}

The most important facilitators for players to implement a load management approach were scientific evidence for improved performance $(88 \%)$ and mitigation of the injuries and illnesses (84\%) as well as the coach being positive to it (86\%; figures 1 and 2 ).

For coaches, the player's motivation to record training data $(88 \%)$, scientific evidence of the preventative effect $(100 \%)$ and scientific evidence of performance enhancement $(71 \%$ figures 1 and 2$)$ were considered most important.

\section{Reach and adoption-experiences from the intervention}

The questions and the responses from players in the intervention group to the load management programme are shown in table 4 . Most players (93\%) indicated that they had spent more than $10 \mathrm{~min}$ per week on the load management

(A) Scientific evidence showing its preventive effect on injuries and illnesses

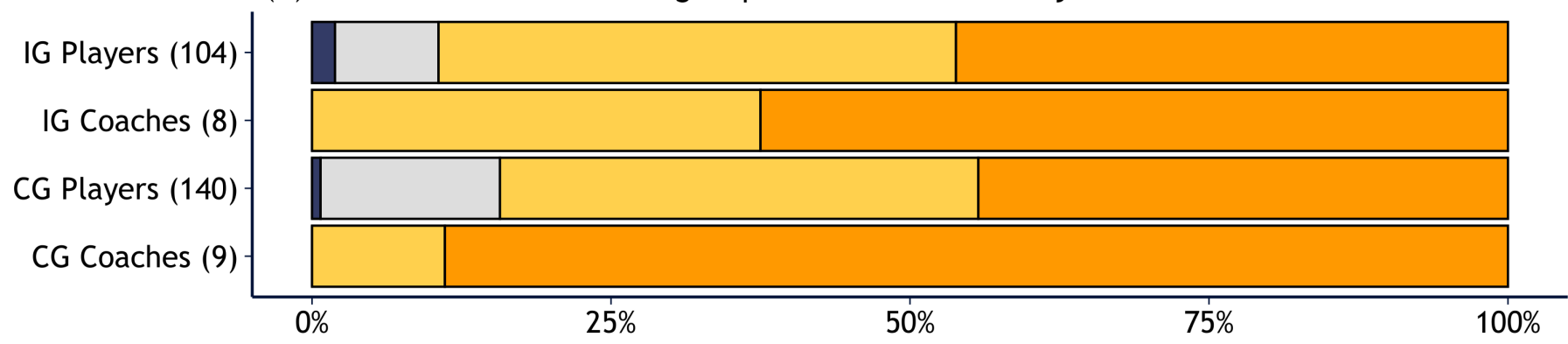

(B) Scientific evidence supporting its effect on performance

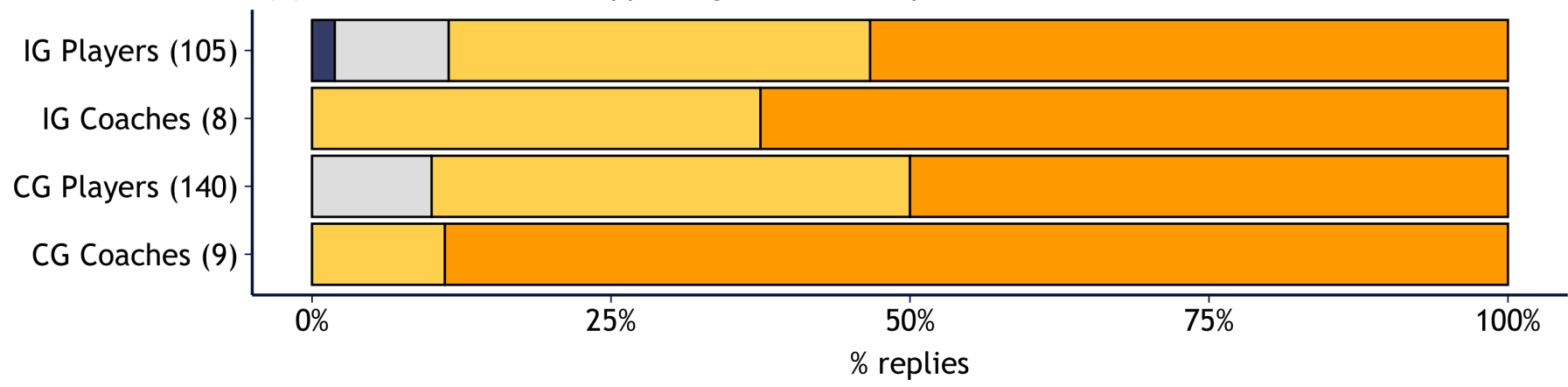

Not important at all $\square$ Not very important $\square$ Neutral $\square$ Important $\square$ Very important

Figure 1 Players' and coaches' response to how important are the following alternatives for your motivation to spend time on overall load management? CG,control group; IG, intervention group. 
(A) Coach is positive about it

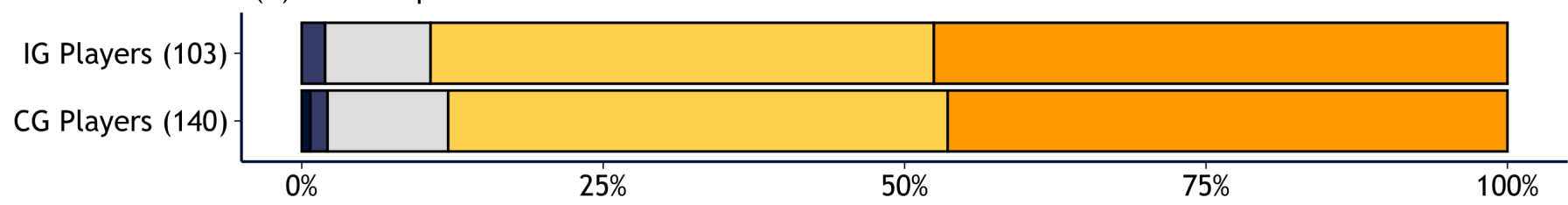

(B) Players are positive to overall load management

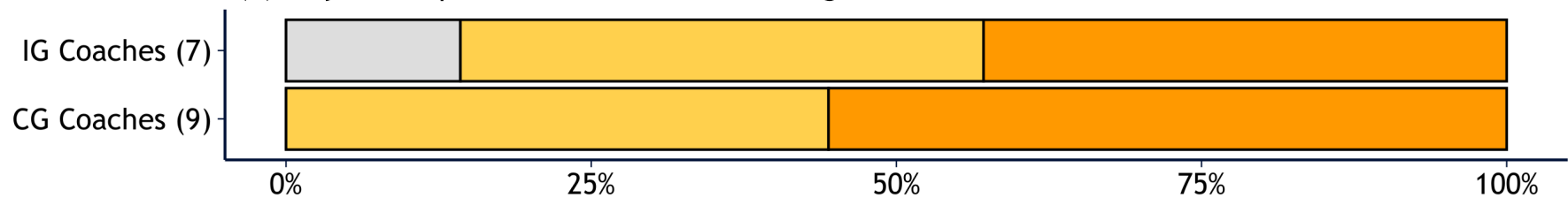

(C) Players are self-motivated to report/register training exposure data

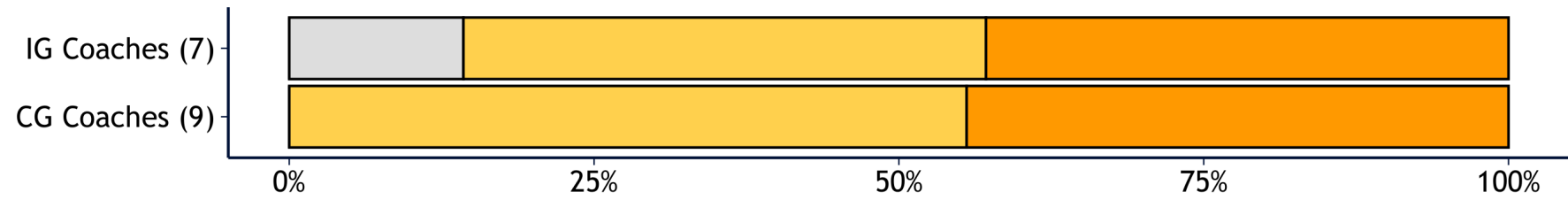

(D) Is expected by club or federation

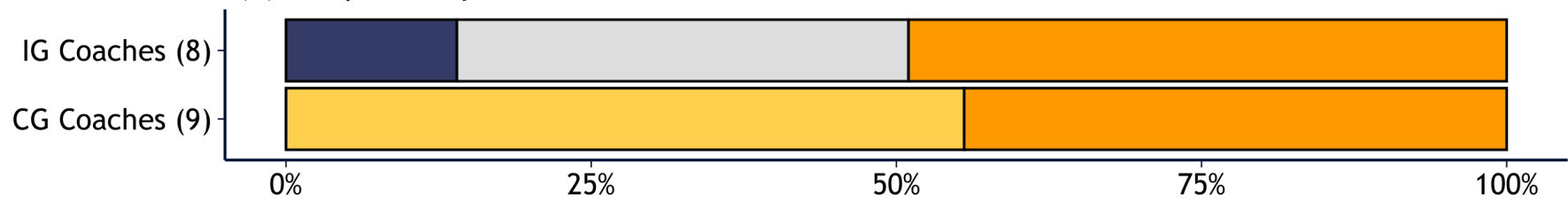

(E) Encompasses intuitive technical software

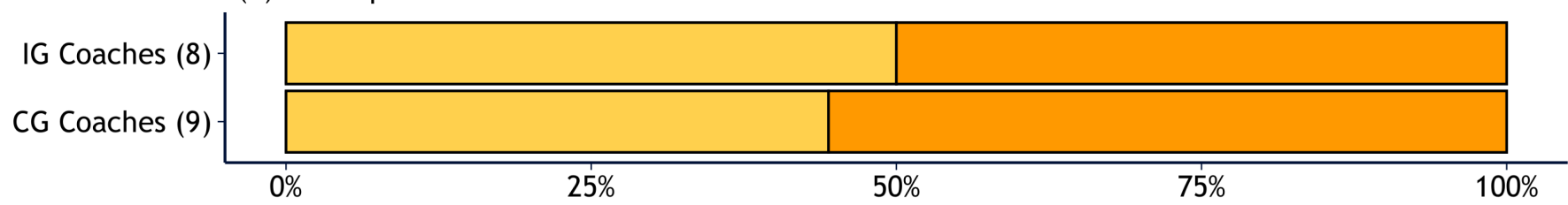

(F) Being given education in theory and hands-on practical training using the system

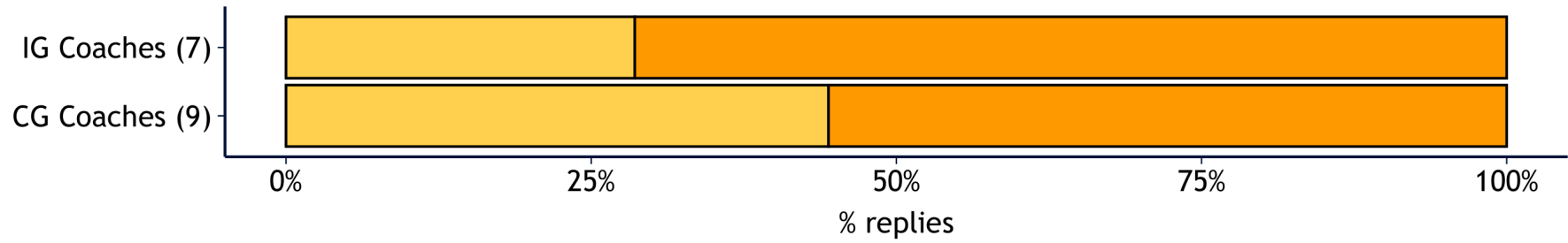

Not important at all

Not very important

Neutral

Figure 2 Players' and coaches' response to How important are the following alternatives for your motivation to spend time on overall load management? CG,control group; IG, intervention group.

programme. Coaches reported that they had spent more than $10 \mathrm{~min}(50 \%)$ or more than $30 \mathrm{~min}$ per week $(50 \%)$. Furthermore, coaches indicated that they had used the specific load management programme as intended by the project group (63\%) and confirmed that all players $(100 \%)$ were aware of the ongoing load management programme. When asked whether they wanted to continue using a specific load management programme in the next season, half of the plavers $(45 \%)$ and coaches $(50 \%)$ replied 'yes definitively', and only $9 \%$ and $13 \%$ of players and coaches, respectively, replied 'no'.

\section{Attitudes to load management and prevention of injuries and illnesses}

An overview of the player's responses about their attitude to the prevention of injuries and illnesses is shown 
in table 2. Of the players included in the study, half $(48 \%)$ considered footballers to be at high risk of injuries in general, and $55 \%$ considered footballers to be at high risk of overuse injuries. More than three quarters of the coaches considered players to be at high risk of injuries in general $(76 \%)$ and overuse injuries $(76 \%)$ in particular. Only one in 10 players considered footballers to be at high risk of illnesses. Furthermore, almost all players $(90 \%)$ and all coaches strongly believed that load management could help reducing injury risk. Regarding overuse injuries, most players $(66 \%)$ and almost all coaches (94\%) strongly believed that a load management approach could have a preventive effect on injuries and illnesses. Despite this, only $28 \%$ of players responded that they were willing to spend more than $10 \mathrm{~min}$ per week on a load management intervention, even if they thought the intervention could reduce injury. However, if a load management intervention could increase players' performance, more than two-thirds $(70 \%)$ of the players were willing to spend more than $10 \mathrm{~min}$ per week doing it. All coaches responded they were willing to spend more than 10 min per week on a load management measure to ensure both preventative and performance outcomes.

\section{DISCUSSION}

This study aimed to investigate players' and coaches' barriers and facilitators to a load management approach for the prevention of injuries and illnesses, and their attitudes and beliefs of load management and injuries and illnesses in general. Our main findings were that players and coaches could contribute to each other's attitude towards an intervention. Both groups need to be motivated for an intervention to be complied with. We also found that players and coaches reported scientific evidence for injury preventive and performance-enhancing effect and time-efficiency as important facilitators. Furthermore, players and coaches believe that footballers are at high risk of sustaining injuries in general and overuse injuries specifically and think that load management could reduce injuries and illnesses.

\section{Facilitators and barriers for implementation}

To successfully implement load management measures, coaches and athletes have a symbiotic relationship. ${ }^{28}$ Players considered their coach's attitude towards load management measures to be one of the most important facilitators and coaches considered their players' attitudes equally important. Furthermore, the players' self-motivation to register training data is considered 'important' by $81 \%$ of the coaches, highlighting the need for both player and coach engagement to implement a load management intervention successfully. This aligns well with the findings of Andersson et al, where they demonstrated a link between player motivation and coach motivation. ${ }^{16}$ For future studies aiming to implement injury preventive interventions, coaches need to be educated about the importance of their positive attitude to motivate the players and other staff to create a spiral of success.

Finch suggested that an intervention must be easy to adopt, and coaches must be informed on why and how the intervention works. ${ }^{29}$ This seems to be supported by our findings, where coaches considered intuitive software solutions and proper training in using them as important facilitators. Moreover, time constraints have been proposed to be one major barrier in implementing preventive interventions. ${ }^{232428}$ Despite the players' trust in the preventive effect of load management, only $57 \%$ would spend more than $10 \mathrm{~min}$, and less than one in three $(28 \%)$ would want to spend more than $20 \mathrm{~min}$ weekly on injury and illness preventive measures. However, if there was an effect on football performance, more than two-thirds $(70 \%)$ of the players were willing to spend more than $10 \mathrm{~min}$ weekly, but less than half (45\%) would want to spend more than $20 \mathrm{~min}$. This reflects a reluctance among players to spend much time on preventive measures regardless of the invention's effectiveness, and specifically more than $20 \mathrm{~min}$. However, the task that the players had to complete in this intervention, the registration of training load in the smartphone application, is likely not to have taken more than $10 \mathrm{~min}$, which means that players might have considered $10 \mathrm{~min}$ as enough and were, understandably, not willing to spend more time than advised.

All coaches were willing to spend more than $10 \mathrm{~min}$ per week on preventive measures if there were scientific evidence for either injury and illness prevention or performance enhancement. Due to their more timedemanding tasks, spending only 10 min would, contrary to the players, not be enough. Only two-thirds of the coaches were willing to spend more than 1 hour per week if there were evidence for prevention $(35 \%)$ or performance benefits $(41 \%)$, which, in our experience, is a reasonable estimate of what would be needed for the coaches to perform the load management intervention. Similar to our previous studies, ${ }^{1625}$ time constraints seem to be a major barrier for the coaches, further highlighting the need for future studies considering the time efficiency of their intervention. However, there is likely a tradeoff between effectiveness, perceived benefit and time spent. Future studies may consider comparing the effect of more time-consuming interventions with interventions being time efficient.

Another aspect to consider when creating an understanding of the importance of implementing preventive measures is to bring on board and engage other stakeholders, such as representatives from federations, associations and clubs. Three quarters $(76 \%)$ of the coaches replied that the expectations of the club or federation were 'important' for their motivation, suggesting that high-level stakeholders should be targeted when introducing preventive measures.

\section{Reach and adoption-experiences from the intervention}

To understand the intervention's reach, we asked the coaches whether the players were aware of the 
Table 2 Players' and coaches' attitude towards injury and illness prevention

\begin{tabular}{|c|c|c|c|c|c|c|}
\hline & & High risk & Some risk & & Low risk & No risk \\
\hline $\begin{array}{l}\text { How muc } \\
\text { injuries in }\end{array}$ & $\begin{array}{l}\text { are footballers } \\
?\end{array}$ & & & & & \\
\hline Players & $I G(n=107)$ & $50(47)$ & $55(51)$ & & $2(2)$ & $0(0)$ \\
\hline & $C G(n=143)$ & $71(50)$ & $69(48)$ & & $2(1)$ & $1(1)$ \\
\hline Coaches & $I G(n=8)$ & $6(75)$ & $2(25)$ & & $0(0)$ & $0(0)$ \\
\hline & $C G(n=9)$ & $7(78)$ & $2(22)$ & & $0(0)$ & $0(0)$ \\
\hline $\begin{array}{l}\text { How muc } \\
\text { to sustair }\end{array}$ & $\begin{array}{l}\mathrm{k} \text { are footballe } \\
\text { ruse injury? }\end{array}$ & & & & & \\
\hline Players & $I G(n=107)$ & $54(51)$ & $50(47)$ & & $3(3)$ & $0(0)$ \\
\hline & $C G(n=143)$ & $84(59)$ & 55 (39) & & $3(2)$ & $1(1)$ \\
\hline Coaches & $I G(n=8)$ & 7 (88) & $1(13)$ & & $0(0)$ & $0(0)$ \\
\hline & $C G(n=9)$ & $6(67)$ & $3(33)$ & & $0(0)$ & $0(0)$ \\
\hline $\begin{array}{l}\text { How muc } \\
\text { to incur a }\end{array}$ & $\begin{array}{l}\mathrm{k} \text { are footballe } \\
\mathrm{s} \text { ? }\end{array}$ & & & & & \\
\hline Players & $I G(n=107)$ & $9(8)$ & $63(59)$ & & $32(30)$ & $3(3)$ \\
\hline & $C G(n=143)$ & $16(11)$ & $74(52)$ & & 47 (33) & $6(4)$ \\
\hline Coaches & $I G(n=8)$ & $3(38)$ & $3(38)$ & & $2(25)$ & $0(0)$ \\
\hline & $C G(n=9)$ & $0(0)$ & $6(67)$ & & $3(33)$ & $0(0)$ \\
\hline $\begin{array}{l}\text { Load mar } \\
\text { injuries in }\end{array}$ & nt can reduce & Strongly agree & Agree & $\begin{array}{l}\text { Neither agree nor } \\
\text { disagree }\end{array}$ & Disagree & Strongly disagree \\
\hline Players & $I G(n=107)$ & $54(51)$ & $46(43)$ & $7(7)$ & $0(0)$ & $0(0)$ \\
\hline & $C G(n=143)$ & $82(57)$ & $45(32)$ & $15(11)$ & $1(1)$ & $0(0)$ \\
\hline Coaches & IG $(n=8)$ & $8(100)$ & $0(0)$ & $0(0)$ & $0(0)$ & $0(0)$ \\
\hline & $C G(n=9)$ & 9 (100.) & $0(0)$ & $0(0)$ & $0(0)$ & $0(0)$ \\
\hline $\begin{array}{l}\text { Load mar } \\
\text { overuse i }\end{array}$ & nt can reduce & & & & & \\
\hline Players & $I G(n=107)$ & $63(59)$ & $40(37)$ & $4(4)$ & $0(0)$ & $0(0)$ \\
\hline & $C G(n=143)$ & $101(71)$ & $34(24)$ & $7(5)$ & $0(0)$ & $0(0)$ \\
\hline Coaches & $I G(n=8)$ & $8(100)$ & $0(0)$ & $0(0)$ & $0(0)$ & $0(0)$ \\
\hline & $C G(n=9)$ & $8(89)$ & $1(11)$ & $0(0)$ & $0(0)$ & $0(0)$ \\
\hline
\end{tabular}

Load management can reduce

illness

\begin{tabular}{|c|c|c|c|c|c|c|}
\hline \multirow[t]{2}{*}{ Players } & IG $(n=107)$ & $28(26)$ & $49(46)$ & $29(7)$ & $1(1)$ & $0(0)$ \\
\hline & CG $(n=143)$ & $41(29)$ & $53(37)$ & $45(32)$ & $3(2)$ & $1(1)$ \\
\hline Coaches & IG $(n=8)$ & $3(38)$ & $3(38)$ & $2(25)$ & $0(0)$ & $0(0)$ \\
\hline \multicolumn{7}{|c|}{$\begin{array}{l}\text { If load management reduced injury and illness - } \\
\text { How much time would you spend weekly doing it? }\end{array}$} \\
\hline & & $0-10 \mathrm{~min}$ & $10-20 \mathrm{~min}$ & $20-30 \mathrm{~min}$ & $30-60 \mathrm{~min}$ & 60 minutes \\
\hline \multirow[t]{2}{*}{ Players } & IG $(n=104)$ & $45(43)$ & $27(26)$ & 17 (16) & $7(7)$ & $4(4)$ \\
\hline & CG $(n=143)$ & $52(36)$ & $46(32)$ & $23(16)$ & $8(6)$ & $9(6)$ \\
\hline \multirow[t]{2}{*}{ Coaches } & IG $(n=8)$ & $0(0)$ & $2(25)$ & $3(38)$ & $1(13)$ & $2(25)$ \\
\hline & $C G(n=9)$ & $0(0)$ & $1(11)$ & $2(22)$ & $2(22)$ & $4(44)$ \\
\hline \multicolumn{7}{|c|}{$\begin{array}{l}\text { If load management increased football performance } \\
\text { - How much time would you spend weekly doing it? }\end{array}$} \\
\hline \multirow[t]{2}{*}{ Coaches } & IG $(n=8)$ & $0(0)$ & $2(25)$ & $2(25)$ & $2(25)$ & $2(25)$ \\
\hline & CG $(n=9)$ & $0(0)$ & $1(11)$ & $2(22)$ & $1(11)$ & $5(56)$ \\
\hline
\end{tabular}


Table 2 Continued

\begin{tabular}{lllll}
\hline High risk & Some risk & Low risk & No risk \\
\hline
\end{tabular}

$N(\%)$.

CG, control group; IG, intervention group.

intervention. All the coaches reported that all players were aware of the protocol, suggesting that the population was reached. Most of the players (74\%) reported having spent less than 5 min weekly on reporting load (table 3). This could be enough to report all footballing activity as advised, as the recording process itself is very time efficient. The coaches who had a much more time-demanding task as part of the intervention reported having followed the instructions on using the load management protocol 1 hour every week (63\%), implying that the plan and intention for the intervention have been followed.

\section{Attitudes towards injuries, illnesses and load management}

The attitudes of most players and coaches are consistent with the current scientific literature on football players' overall risk of injury and risk of overuse injury. ${ }^{13}$ Furthermore, coaches' and players' attitudes are also consistent with the literature that illness is not a major problem in football. ${ }^{30}$ Players and coaches were aligned in their belief that injury overall and overuse injury specifically, but not illness, could be mitigated by load management. Whether this belief is consistent with scientific evidence is currently unclear. ${ }^{14} 31-33$ Similarly, in an investigation among high-level academy and elite players in Germany, Zech and Wellmann ${ }^{34}$ found that players believe that injury prevention is important and that players' considerations of what increases injury risk are not consistent with current scientific literature. When investigating coaches' perceptions on injury risk and prevention, Klein $e t a l^{35}$ reported that coaches rated injury prevention as highly relevant and that load management should be given greater priority in the coach education. Furthermore, the coaches' and players' belief on an effect can potentially be a facilitator in itself and may, thus, aid the implementation. ${ }^{36}$ Also, players and coaches have a common understanding of the true scale of injuries and illnesses in football, which is a fundamental starting point when implementing preventive measures.

\section{METHODOLOGICAL CONSIDERATIONS}

The questionnaires used were tested in a small pilot study, and we cannot be certain all the participants understood the questions and similarly interpreted them. The two questions surrounding the risk of injuries overall and overuse injures specifically is likely to have been somewhat misinterpreted as players considered footballers to

Table 3 Players' and coaches' perceptions of the load management intervention

\begin{tabular}{|c|c|c|c|c|c|c|c|c|}
\hline & & No time & $<5$ min & $10 \mathrm{~min}$ & $20 \mathrm{~min}$ & $30 \mathrm{~min}$ & $45 \mathrm{~min}$ & 1 hour or more \\
\hline Players & $I G(n=111)$ & $7(6)$ & $0(0)$ & $83(75)$ & 16 (15) & 5 (5) & $0(0)$ & $0(0)$ \\
\hline Coaches & IG $(n=8)$ & $0(0)$ & $0(0)$ & $3(38)$ & 1 (13) & $2(25)$ & $0(0)$ & $2(25)$ \\
\hline
\end{tabular}

Were the players aware of the programme?

\begin{tabular}{|c|c|c|c|c|c|}
\hline & & Yes, all players & $\begin{array}{l}\text { More than half } \\
\text { of the players }\end{array}$ & $\begin{array}{l}\text { Less than } \\
\text { half of the } \\
\text { players }\end{array}$ & $\begin{array}{l}\text { None of } \\
\text { the players }\end{array}$ \\
\hline Coaches & $I G(n=8)$ & $8(100)$ & $0(0)$ & $0(0)$ & $0(0)$ \\
\hline \multicolumn{6}{|c|}{ Was the load management programme used as intended? (Minimum 1 hour before each training week) } \\
\hline & & $\begin{array}{l}\text { Yes, every } \\
\text { week }\end{array}$ & $\begin{array}{l}\text { No, every other } \\
\text { week }\end{array}$ & $\begin{array}{l}\text { No, once } \\
\text { per month }\end{array}$ & $\begin{array}{l}\text { Was not } \\
\text { used at all }\end{array}$ \\
\hline Coaches & IG $(n=8)$ & $5(63)$ & $1(13)$ & $2(25)$ & $0(0)$ \\
\hline \multicolumn{6}{|c|}{ Are you planning to use an overall load management programme next season? } \\
\hline & & $\begin{array}{l}\text { Yes, } \\
\text { definitively }\end{array}$ & $\begin{array}{l}\text { Yes, but } \\
\text { in a less } \\
\text { challenging } \\
\text { way than this } \\
\text { year }\end{array}$ & No & $\begin{array}{l}\text { Do not } \\
\text { know }\end{array}$ \\
\hline Players & IG $(n=105)$ & $47(45)$ & $23(22)$ & $9(9)$ & $26(25)$ \\
\hline Coaches & IG $(n=8)$ & $4(50)$ & $0(0)$ & $1(13)$ & $3(38)$ \\
\hline
\end{tabular}

$N(\%)$.

CG, control group; IG, intervention group. 
have a higher risk of overuse injuries than injuries overall. Furthermore, the terms 'scientific evidence' and 'performance' could have been more thoroughly refined in a focus group or pilot study as they might mean different things to different participants. The survey-based methodology is limited because it is only giving information in the specific areas assessed, meaning important components might have been missed, as they were not deemed as important when constructing the survey. A qualitative study design would have added value and might have been a more appropriate approach to achieve a deeper and more comprehensive understanding of the player's and coaches' perceptions.

When interpreting this study's results, the study's compliance was also suboptimal, and selection bias should be considered. We suspect that the players and coaches who responded to the questionnaire were more likely to have been positive to the intervention compared with nonrespondents, which may have influenced the results. Specifically, the low compliance of the players in the intervention group is a limitation. The intervention group players had lower compliance in the RCT as well, suggesting questionnaire fatigue from registering training data daily. The low number of coaches involved in this study means that we do not have too robust data on this group, so our findings of the coaches should be interpreted with caution. Also, the questionnaire did not include questions giving detailed information about maintenance, one of the key dimensions of the RE-AIM framework.

A strength of the study is the balanced number of male and female participants, representing the population of elite youth players in Norway, increasing the external validity. An additional strength is the low risk of contamination between players due to the late-night distribution of the questionnaire. This separates this study from a similar study that used paper-based questionnaires distributed in the dressing room with the whole team present. ${ }^{23}$ Despite a nonoptimal response rate, this study still includes more than 250 participants supporting the strength of our findings.

\section{PERSPECTIVES}

As with previous research on preventive measures in sports, high compliance is necessary to investigate its real effectiveness. Given that coaches and players think that injury in general and overuse injury specifically are prevalent in football, and that load management measures can reduce them. It seems that the potential for successful implementation is present. However, there are two major circular problems. First, to adhere to the intervention, the players and coaches want evidence for effectiveness, but to investigate its effectiveness, we need players and coaches to adhere to the intervention. Second, to convince players to adhere to the intervention, players want coaches who are positive towards the intervention, motivating them to participate. On the contrary, to get the buy-in from the coaches, players adhering to the intervention is key.

When implementing a load management intervention, we can, based on the findings in this paper, give the following advice: (1) focus on the technical solutions for both coaches and players and make all participant involvement of an intervention time-efficient, (2) create buy-in from club and federation stakeholders as well as coaches and players and (3) focus on both performance and prevention when communicating with all relevant stakeholders. To engage end users' and gain populationspecific knowledge, future implementations should consider qualitative surveying parts of the RE-AIM framework before planning the intervention. Although more detailed answerers regarding experiences from an intervention must be obtained after participating, initial key facilitators and barriers can be identified and planned for before the study starts.

Further investigations into coaches' and players' attitudes and beliefs of load management measures and the implementation of an intervention to mitigate injuries and illnesses are warranted as well as experimental investigations on the potential preventive and performance effect of a load management approach.

\section{Twitter Torstein Dalen-Lorentsen @torsteindalen}

Acknowledgements The authors are grateful to all the players and coaches who participated in the study.

Contributors TD-L, BC, JB and TEA planned the study. The data collection was done by TD-L and AR. All authors have been involved in the data analyses, drafting and revision of the manuscript, and all have approved the final version.

Funding The 0slo Sports Trauma Research Centre has been established at the Norwegian School of Sport Sciences through generous grants from the Royal Norwegian Ministry of Culture, the South-Eastern Norway Regional Health Authority, the International Olympic Committee, the Norwegian Olympic Committee and Confederation of Sport, and Norsk Tipping AS.

Competing interests The 0slo Sports Trauma Research Centre (OSTRC) has a research partnership together with Fitstats Inc. This partnership is based on the development of injury surveillance tools, which were not used in this study. Fitstats provided the use of the athlete management system free for this study. However, we are not involved in their load management products, and have no financial interest of any kind in Fitstats.

Patient and public involvement Patients and/or the public were involved in the design, or conduct, or reporting, or dissemination plans of this research. Refer to the Methods section for further details.

Patient consent for publication Not required.

Provenance and peer review Not commissioned; externally peer reviewed. Data availability statement All data are available upon request.

Open access This is an open access article distributed in accordance with the Creative Commons Attribution Non Commercial (CC BY-NC 4.0) license, which permits others to distribute, remix, adapt, build upon this work non-commercially, and license their derivative works on different terms, provided the original work is properly cited, appropriate credit is given, any changes made indicated, and the use is non-commercial. See: http://creativecommons.org/licenses/by-nc/4.0/.

\section{ORCID iD}

Torstein Dalen-Lorentsen http://orcid.org/0000-0003-4062-7601 


\section{REFERENCES}

1 Jones S, Almousa S, Gibb A, et al. Injury incidence, prevalence and severity in high-level male youth football: a systematic review. Sports Med 2019;49:1879-99.

2 Ekstrand J, Hägglund M, Waldén M. Injury incidence and injury patterns in professional football: the UEFA injury study. $\mathrm{Br} J$ Sports Med 2011;45:553-8.

3 Moseid CH, Myklebust G, Fagerland MW, et al. The prevalence and severity of health problems in youth elite sports: a 6-month prospective cohort study of 320 athletes. Scand J Med Sci Sports 2018;28:1412-23.

4 Røksund OD, Kristoffersen M, Bogen BE, et al. Higher drop in speed during a repeated sprint test in soccer players reporting former hamstring strain injury. Front Physiol 2017;8:25.

5 Maffulli N, Longo UG, Gougoulias N, et al. Long-term health outcomes of youth sports injuries. Br J Sports Med 2010;44:21-5.

6 Fyfe JJ, Opar DA, Williams MD, et al. The role of neuromuscular inhibition in hamstring strain injury recurrence. J Electromyogr Kinesiol 2013;23:523-30.

7 Ward P, Hodges NJ, Starkes JL, et al. The road to excellence: deliberate practice and the development of expertise. High Ability Studies 2007;18:119-53.

8 Delecroix B, McCall A, Dawson B, et al. Workload and non-contact injury incidence in elite football players competing in European leagues. Eur J Sport Sci 2018;18:1280-7.

9 Fanchini M, Rampinini E, Riggio M, et al. Despite association, the acute:chronic work load ratio does not predict non-contact injury in elite footballers. Science and Medicine in Football 2018;2:108-14.

10 Jaspers A, Kuyvenhoven JP, Staes F. Examination of the external and internal load indicators' association with overuse injuries in professional soccer players. Journal of Science and Medicine in Sport 2017:1-7.

11 Malone S, Owen A, Newton M, et al. The acute:chonic workload ratio in relation to injury risk in professional soccer. J Sci Med Sport 2017;20:561-5.

12 Weston M. Training load monitoring in elite English soccer: a comparison of practices and perceptions between coaches and practitioners. Science and Medicine in Football 2018;2:216-24.

13 Akenhead R, Nassis GP. Training load and player monitoring in highlevel football: current practice and perceptions. Int J Sports Physiol Perform 2016;11:587-93.

14 Dalen-Lorentsen T, Bjørneboe J, Clarsen B, et al. Does load management using the acute:chronic workload ratio prevent health problems? A cluster randomised trial of 482 elite youth footballers of both sexes. Br J Sports Med 2021;55:108-14.

15 Gabbett TJ. The training-injury prevention paradox: should athletes be training smarter and harder? Br J Sports Med 2016;50:273-80.

16 Andersson SH, Bahr R, Clarsen B, et al. Preventing overuse shoulder injuries among throwing athletes: a cluster-randomised controlled trial in 660 elite handball players. Br J Sports Med 2017;51:1073-80.

17 Harøy J, Clarsen B, Wiger EG, et al. The adductor strengthening programme prevents groin problems among male football players: a cluster-randomised controlled trial. Br J Sports Med 2019;53:150-7.

18 Steffen K, Emery CA, Romiti M, et al. High adherence to a neuromuscular injury prevention programme (FIFA 11+) improves functional balance and reduces injury risk in Canadian youth female football players: a cluster randomised trial. Br J Sports Med 2013:47:794-802.

19 Soligard T, Nilstad A, Steffen K, et al. Compliance with a comprehensive warm-up programme to prevent injuries in youth football. Br J Sports Med 2010;44:787-93.
20 Silvers-Granelli HJ, Bizzini M, Arundale A, et al. Higher compliance to a neuromuscular injury prevention program improves overall injury rate in male football players. Knee Surg Sports Traumatol Arthrosc 2018;26:1975-83.

21 Glasgow RE, Harden SM, Gaglio B, et al. RE-AIM planning and evaluation framework: adapting to new science and practice with a 20-year review. Front Public Health 2019;7:64.

22 Finch CF, Donaldson A. A sports setting matrix for understanding the implementation context for community sport. Br J Sports Med 2010;44:973-8

23 Harøy J, Wiger EG, Bahr R, et al. Implementation of the Adductor Strengthening Programme: Players primed for adoption but reluctant to maintain - A cross-sectional study. Scand J Med Sci Sports 2019;29:1092-100

24 Andersson SH, Bahr R, Olsen MJ, et al. Attitudes, beliefs, and behavior toward shoulder injury prevention in elite handball: fertile ground for implementation. Scand J Med Sci Sports 2019;29:1996-2009.

25 O'Brien J, Young W, Finch CF. The use and modification of injury prevention exercises by professional youth soccer teams. Scand J Med Sci Sports 2017;27:1337-46.

26 , Bahr R, Clarsen B, et al, International Olympic Committee Injury and Illness Epidemiology Consensus Group. International Olympic Committee consensus statement: methods for recording and reporting of epidemiological data on injury and illness in sports 2020 (including the STROBE extension for sports injury and illness surveillance (STROBE-SIIS)). Orthop J Sports Med 2020;8:2325967120902908.

27 Jilcott S, Ammerman A, Sommers J, et al. Applying the RE-AIM framework to assess the public health impact of policy change. Ann Behav Med 2007;34:105-14.

28 O'Brien J, Finch CF. The implementation of musculoskeletal injury-prevention exercise programmes in team ball sports: a systematic review employing the RE-AIM framework. Sports Med 2014;44:1305-18.

29 Finch C. A new framework for research leading to sports injury prevention. J Sci Med Sport 2006;9:3-9.

30 Bjørneboe J, Kristenson K, Waldén M, et al. Role of illness in male professional football: not a major contributor to time loss. $\mathrm{Br} J$ Sports Med 2016;50:699-702

31 Impellizzeri FM, Tenan MS, Kempton T, et al. Acute:Chronic Workload Ratio: Conceptual Issues and Fundamental Pitfalls. Int J Sports Physiol Perform 2020:1-7.

32 Impellizzeri FM, Woodcock S, Coutts AJ. Acute to random workload ratio is 'as' associated with injury as acute to actual chronic workload ratio: time to dismiss ACWR and its components. SportRxiv 2020.

33 Wang C, Vargas JT, Stokes T, et al. Analyzing Activity and Injury: Lessons Learned from the Acute:Chronic Workload Ratio. Sports Med 2020;50:1243-54.

34 Zech A, Wellmann K. Perceptions of football players regarding injury risk factors and prevention strategies. PLoS One 2017;12:e0176829.

35 Klein C, Henke T, Luig P, et al. Leaving injury prevention theoretical? Ask the coach! - A survey of 1012 football coaches in Germany. German Journal of Exercise and Sport Research 2018;48:489-97.

36 McKay CD, Steffen K, Romiti M, et al. The effect of coach and player injury knowledge, attitudes and beliefs on adherence to the FIFA $11+$ programme in female youth soccer. Br J Sports Med 2014:48:1281-6. 